\title{
Inverted Opal Luminescent Ce-Doped Silica Glasses
}

\author{
R. Scotti, ${ }^{1}$ C. Canevali, ${ }^{1}$ S. Polizzi, ${ }^{2}$ M. Bettinelli, ${ }^{3}$ A. Speghini, ${ }^{3}$ and F. Morazzoni ${ }^{1}$ \\ ${ }^{1}$ INSTM, Dipartimento di Scienza dei Materiali, Università degli Studi di Milano-Bicocca, via Cozzi 53, 20125 Milano, Italy \\ ${ }^{2}$ INSTM, Dipartimento di Chimica Fisica, Università di Ca' Foscari, via Torino 155/b, 30172 Venezia-Mestre, Italy \\ ${ }^{3}$ INSTM, Dipartimento di Scientifico e Tecnologico, Università degli Studi di Verona, Strada le Grazie 15, 37134 Verona, Italy
}

Received 14 February 2006; Accepted 9 May 2006

Inverted opal Ce-doped silica glasses (Ce : Si molar ratio $1 \cdot 10^{-3}$ ) were prepared by a sol-gel method using opals of latex microspheres as templates. The rare earth is homogeneously dispersed in silica host matrix, as evidenced by the absence of segregated $\mathrm{CeO}_{2}$, instead present in monolithic Ce-doped SG with the same cerium content. This suggests that the nanometric dimensions of bridges and junctions of the host matrix in the inverted opal structures favor the RE distribution avoiding the possible segregation of $\mathrm{CeO}_{2}$.

Copyright (C) 2006 R. Scotti et al. This is an open access article distributed under the Creative Commons Attribution License, which permits unrestricted use, distribution, and reproduction in any medium, provided the original work is properly cited.

\section{INTRODUCTION}

Luminescent rare-earth (RE)-doped silica glass (SG) materials are employed in many applications for optical devices. In particular, $\mathrm{Ce}^{3+}$-doped $\mathrm{SG}$ is a promising material to be used as a scintillator for the detection of $X$-rays, $\gamma$-rays, or neutrons $[1,2]$ and tunable solid state lasers operating in the near-UV, violet, and blue regions $[3,4]$. Notable properties of luminescent $\mathrm{Ce}^{3+}$ ions are the fast decay time and the high efficiency of the allowed $5 \mathrm{~d}-4 \mathrm{f}$ transition in the UV-visible region.

SG hosts for luminescent centers are alternative to crystalline systems, owing to their attractive characteristics as low cost, flexible shape, and possible employment in fiber technology. A possible drawback is the presence of point defects and $\mathrm{OH}$ groups in the matrix, which cause an increased nonradiative deactivation rate through the creation of multiple vibrational quanta of the $\mathrm{OH}$ stretching vibration, lowering the energy transfer efficiency from the host glass to the emission centers [5]. In order to synthesize high-purity glasses, embedding controlled amounts of RE activator ions, the solgel technique can be used instead of conventional quenching of oxide melts [6-8]. In fact, according to this method, the precursor reactions and the thermal processes for glass densification occur at lower temperatures, in principle avoiding or lowering the probability of point defects in the glass.

A second drawback of RE-doped SG, which unfavorably affects the luminescence yield, is the ions aggregation due to the poor solubility of RE cations in the glass matrix. When the RE concentration increases, the interionic distance becomes comparable to the critical distance, at which the radiative decay probability equals the energy transfer rate, leading to nonradiative processes [9]. Besides, in the case of $\mathrm{Ce}^{3+}$ doping, also the oxidation to nonluminescent $\mathrm{Ce}^{4+}$ can lead to the segregation of nanocrystalline $\mathrm{CeO}_{2}$ in the glass matrix, causing significant luminescence quenching $[8,10]$.

In order to embed $\mathrm{Ce}^{3+}$ ions into the glass matrix, avoiding ion aggregation and $\mathrm{CeO}_{2}$ segregation, codoping of SG with different heteroatoms was demonstrated to be a good tool to produce highly efficient optical materials $[11,12]$, creating a different solvation structure [13] and a preferential coordination of the codopant around RE ions. Our recent study on Ce-doped boro-(BSG), phospho(PSG), and borophosphosilicate (BPSG) glasses demonstrated that the $\mathrm{Ce}^{3+}$ emission yield was enhanced in PSG and BPSG with respect to SG and BSG, because of the coordination of $\mathrm{P}=\mathrm{O}$ groups. These are located in phosphoryl $\left[\mathrm{O}=\mathrm{PO}_{3 / 2}\right]$, metaphosphate $\left[\mathrm{O}=\mathrm{PO}_{2 / 2} \mathrm{O}\right]^{-}$, and pyrophosphate $\left[\mathrm{O}=\mathrm{PO}_{1 / 2} \mathrm{O}_{2}\right]^{2-}$ units, linked to the silica network, and preferentially interact with $\mathrm{Ce}^{3+}$ ions, very probably hindering both $\mathrm{CeO}_{2}$ segregation and the oxidation of isolated $\mathrm{Ce}^{3+}$ ions to $\mathrm{Ce}^{4+12}$.

In the frame of the research on new luminescent materials with novel and tunable optical properties, intensively pursued by industry and university laboratories, many efforts have been made in the field of the synthesis of porous materials [14-19] with different pore sizes and ordered nanoscale architectures, where RE luminescent centers are embedded into the matrix or grafted onto the pore walls. In this paper, we focused our attention on the porous and nanosized 
host structures of SG inverted opals; a material built by nanosized bridges and junctions around a regular and compact arrangement of air spheres. Many glasses and ceramics have been prepared as opal and inverted opals [20], in particular for their properties of photonic crystals with a luminescent probe inside the pore, or embedded in the matrix $[18,19]$.

In the present work, inverted opals of Ce-doped SG (Ce : Si molar ratio $1 \cdot 10^{-3}$ ) were synthesized by a sol-gel method, using latex opals as templates. The aim was to study the influence of the ordered porosity and the nanoscale dimensions of the glass matrix on the stabilization and dispersion of the $\mathrm{RE}$ luminescent centers, aiming to improve the $\mathrm{Ce}^{3+}$ dispersion in the host glass matrix and to lower the oxidative $\mathrm{CeO}_{2}$ segregation observed in SG $[10,11]$.

The structure of the inverted opal architecture and the possible occurrence of crystalline $\mathrm{CeO}_{2}$ phase were investigated by scanning electron microscopy (SEM) and highresolution transmission electron microscopy (HRTEM). Electron paramagnetic resonance (EPR) was used to get information about the environment of paramagnetic $\mathrm{Ce}^{3+}$ ions embedded in glass. Finally, the luminescence properties were verified by measuring the emission decay curve of the $\mathrm{Ce}^{3+}$ $4 \mathrm{~d}-5 \mathrm{f}$ transition.

\section{EXPERIMENTAL}

The colloidal suspension of polstyrene latex microspheres (350 nm diameter) in water (2.5 wt\%) was from Alfa Aesar. Polystyrene opal was first prepared by centrifugation $(3 \mathrm{~h}$, $2000 \mathrm{rpm}$ ) of the colloidal microsphere aqueous suspensions. After removal of the surnatant solvent, the opal was dried at $308 \mathrm{~K}$ for $24 \mathrm{~h}$, then placed in a vial and further dried in vacuum $\left(10^{-1}\right.$ torr $)$ at room temperature for 30-60 min.

Inverted opal Ce-doped $\mathrm{SiO}_{2}$ was obtained by dropwise impregnation of the polystyrene template under a dry $\mathrm{N}_{2}$ atmosphere with the minimum amount of the solution of tetraethylortosilicate, TEOS, (99.999\% Aldrich); acetic acid, $\mathrm{CH}_{3} \mathrm{COOH}$ (99.99\%, Aldrich); and millQ water containing the suitable amount of $\mathrm{Ce}\left(\mathrm{NO}_{3}\right)_{3} \cdot 6 \mathrm{H}_{2} \mathrm{O}$. TEOS : $\mathrm{CH}_{3} \mathrm{COOH}: \mathrm{H}_{2} \mathrm{O}$ molar ratio was $1: 4: 5$; Ce : Si molar ratio was $1 \cdot 10^{-3}$. After impregnation, samples were kept in a thermostatic chamber at $308 \mathrm{~K}$ for $24 \mathrm{~h}$ in order to complete the sol-gel transition and, finally, they were heated $\left(10^{\circ} \mathrm{C} / \mathrm{h}\right)$ at $1073 \mathrm{~K}$ for $4 \mathrm{~h}$ in flowing $\mathrm{O}_{2}\left(30 \mathrm{~cm}^{3} / \mathrm{min}\right)$.

The sample morphology was analyzed by SEM, using a Vega TS5136 XM Tescan microscope in a high-vacuum configuration. The electron beam excitation was $30 \mathrm{kV}$ at a beam current of $25 \mathrm{pA}$ and the working distance was $12 \mathrm{~nm}$. In this configuration the beam spot was $38 \mathrm{~nm}$. Previous to the SEM analysis, samples were gold-sputtered.

HRTEM analysis was performed at $300 \mathrm{kV}$ using a Jeol 3010 apparatus with a high-resolution pole piece $(0.17 \mathrm{~nm}$ point-to-point resolution), equipped with a Gatan slowscan 794 CCD camera. Elemental composition was determined by an Oxford Instruments EDS microanalysis detector (Mod. 6636). Glass samples were ground in an agate mortar and the resulting fine powder suspended in isopropanol. A $5 \mu \mathrm{L}$ drop of this suspension was deposited on a holey carbon film supported on $3 \mathrm{~mm}$ copper grid for TEM investigation.
$\mathrm{Ce}^{3+}$ EPR spectra were recorded at $4.2 \mathrm{~K}$ on inverted opal samples by a conventional Bruker EMX spectrometer operating at the $X$ band frequency, equipped with an Oxford cryostat operating in the $4.2 \div 373 \mathrm{~K}$ temperature range. The $g$ values were measured by using diphenylpicrylhydrazyl (DPPH) as standard.

The luminescence decay curves in the UV region were measured at room temperature exciting at $290 \mathrm{~mm}$ with the second harmonic of a dye laser (using Rodamine $6 \mathrm{G}$ as the dye) pumped with the second harmonic $(532 \mathrm{~nm}$ ) of a pulsed Nd-YAG laser. A fiber optic probe was employed to collect the emission. The signal was analyzed by a half-meter monochromator equipped with a 150 lines $/ \mathrm{mm}$ grating. A GaAs photomultiplier and a digital oscilloscope were used to measure the emission decay curves. The decay times were obtained from the emission decay curves using a deconvolution procedure which takes into account the shape and the duration of the excitation pulse.

\section{RESULTS AND DISCUSSION}

The micro-structural characterization of inverted opal Cedoped SG (Ce : Si molar ratio $\left.1 \cdot 10^{-3}\right)$ was performed by SEM and HRTEM. Figure 1 shows representative SEM and HRTEM micrographs obtained for opals of $350 \mathrm{~nm}$ latex microspheres. The figure clearly shows the structure of bridges and junctions of amorphous silica surrounding a regular array of circa $280 \mathrm{~nm}$ diameter hollow spheres, about $20 \%$ smaller than that of the template spheres, due to the shrinkage of the glass matrix. The SEM pictures show the large extension and homogeneity of the sample architecture (Figure 1(a)). HRTEM analysis demonstrates that, at the conditions of the preparation procedure, the silica matrix is amorphous and no undesired segregation of nanocrystalline $\mathrm{CeO}_{2}$ occurred in inverted opal Ce-doped SG samples (Figure 1(b)). The latter behavior is different from that of monolithic Ce-doped SG prepared by sol-gel method with the same RE content $[10,11]$, even if it cannot be excluded that $\mathrm{CeO}_{2}$ particles too small to be detected are present. As the elemental analyses demonstrated that no cerium was lost during sample preparation, it appears that the tendency of $\mathrm{CeO}_{2}$ to segregate in the nanosized bridges and junctions of the inverted opal SG matrix is inhibited, favoring RE dispersion.

The EPR analysis of the paramagnetic $\mathrm{Ce}^{3+}$ centers was performed at $4.2 \mathrm{~K}$. In fact, no resonance lines were detected above $20 \mathrm{~K}$, due to the rapid relaxation time $T_{1}$ which broadens the line width (line width $\propto T_{1}^{-1}$ ), according to the behavior of most lanthanides [21] with the exception of S-state ions with a half-field subshell $4 \mathrm{f}$ [7]. EPR spectra of inverted opal Ce-doped SG showed a complex signal spanning about $10^{4} \mathrm{G}$ and consisting of several overlapped broad resonances (Figure 2(a)).

The assignment of particular sets of lines to well-defined $\mathrm{Ce}^{3+}$ centers is not easy, as the wave function of the ${ }^{2} \mathrm{~F}_{5 / 2}$ ground state results, for a specific crystal field symmetry, from the linear combination of the $\left|M_{j}= \pm 1 / 2\right\rangle, \mid M_{j}=$ $\pm 3 / 2\rangle$, and $\left|M_{j}= \pm 5 / 2\right\rangle$ eigenfunctions [22]. Thus the 


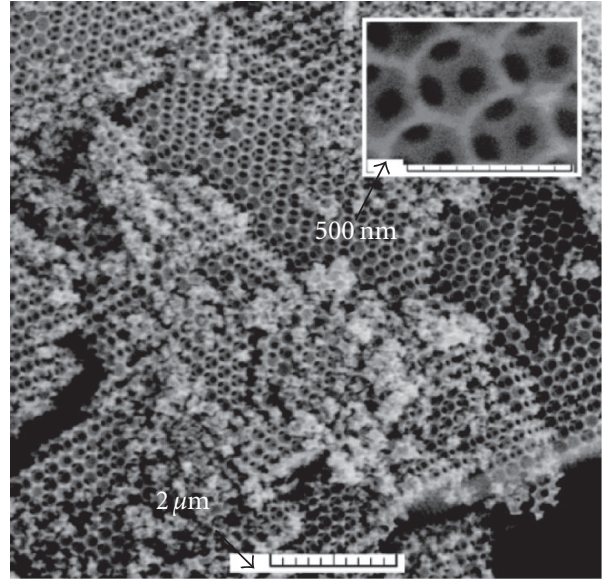

(a)

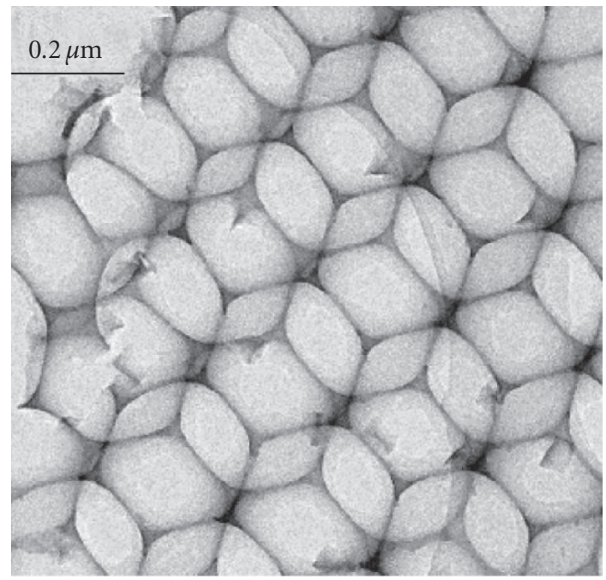

(b)

FIgURE 1: (a) SEM and (b) HRTEM michrographs of Ce-doped SG (Ce : Si molar ratio $\left.1 \cdot 10^{-3}\right)$ inverted opals.

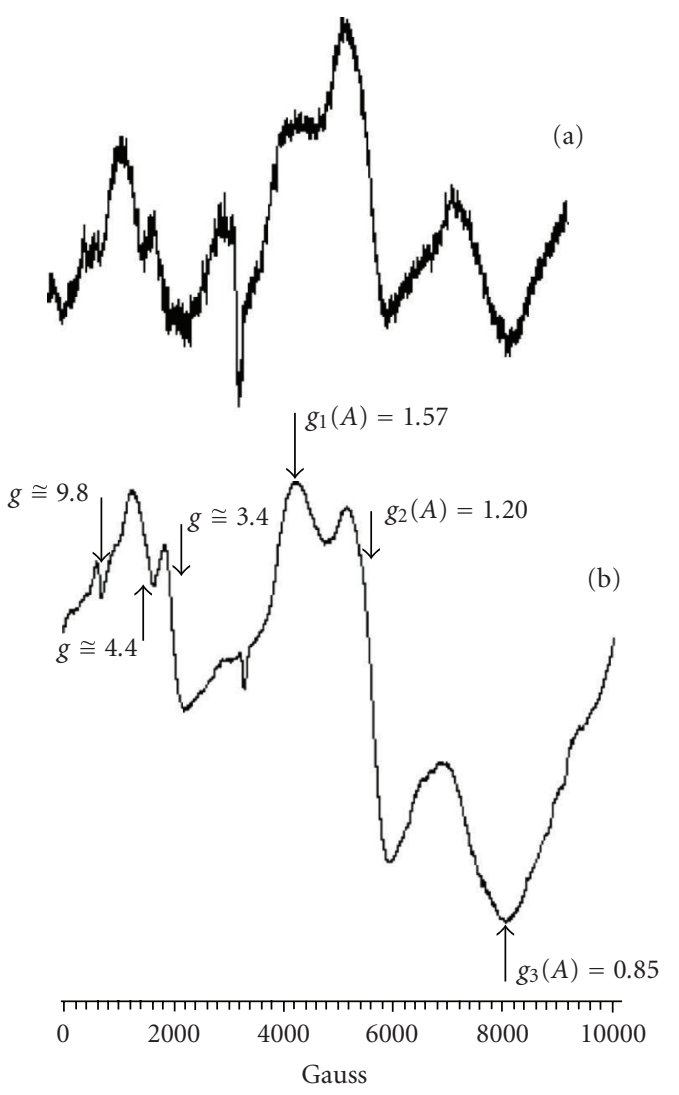

FIGURE 2: EPR spectra recorded at $4.2 \mathrm{~K}$ of (a) Ce-doped SG (Ce : Si molar ratio $1 \cdot 10^{-3}$ ) inverted opals and (b) monolithic Ce-doped SG (Ce : Si molar ratio $1 \cdot 10^{-3}$ ) prepared by sol-gel method [11].

experimental $g$-tensors values for $\mathrm{Ce}^{3+}$ can vary in a wide range of values [23-26], in particular in amorphous hosts where the paramagnetic centers experience several and differently distorted symmetry fields. In a previous paper [11] on monolithic Ce-doped SG prepared by sol-gel method, we suggested that the resonances at $g_{1}=1.57, g_{2}=1.20$, $g_{3}=0.85$ could be attributed to a single species in orthorhombic symmetry (species A in Figure 2), as $g$ values are very similar to those reported by Yamaga et al. [23] for a Ce-doped $\mathrm{LiCaAlF}_{6}$ single crystal. Besides, the weaker overlapped lines at low magnetic field, ranging from $g \sim 10.5$ to $g \sim 3$, were due to different $\mathrm{Ce}^{3+}$ species [11] and in particular the values $g \sim 3.4$ and $g \sim 4.4$ are reminiscent of the $g_{z z}$ components reported by Misra et al. $[24,25]$ for $\mathrm{Ce}^{3+}$ ions in the orthorhombic crystal field of $\mathrm{CeBa}_{2} \mathrm{Cu}_{3} \mathrm{O}_{7-\delta}$ and $\mathrm{CeBa}_{2} \mathrm{Cu}_{4} \mathrm{O}_{8} \cdot$, the related $g_{x x}$ and $g_{y y}$ being covered by the stronger lines of signal A. It is interesting to note that the EPR signal due to $\mathrm{Ce}^{3+}$ ions in inverted opal SG is the same as that in monolithic SG, indicating the same environment of RE in the glass matrix.

The luminescence properties of the inverted opal Cedoped SG (Ce : Si $=1 \cdot 10^{-3}$ molar ratio) were studied by measuring the emission decay curve at room temperature of the $\mathrm{Ce}^{3+}$ allowed $4 \mathrm{~d}-5 \mathrm{f}$ transition $\left(\lambda_{\mathrm{exc}}=290 \mathrm{~nm} ; \lambda_{\mathrm{em}}=\right.$ $415 \mathrm{~nm})$. The emission decay time $(\tau)$ obtained from the emission decay curve, shown in the semilog plot of Figure 3, using a deconvolution procedure, is $47 \pm 2 \mathrm{~ns}$. This value was very similar to that reported for $\mathrm{Ce}^{3+}$ in silica glass [27] and that found for monolithic Ce-doped SG prepared by sol-gel method [11]. This confirms that the observed luminescence is really due to $\mathrm{Ce}^{3+}$ centers and indicates that the environment of $\mathrm{Ce}^{3+}$ ions is similar in both inverted opal and monolithic host matrices, as suggested by EPR investigation.

\section{CONCLUDING REMARKS}

Inverted opal Ce-doped SG (Ce : Si molar ratio $1 \cdot 10^{-3}$ ) was prepared by a sol-gel method using a latex opal as template, which allowed a single-step introduction of the rare earth in the silica matrix.

Morphological and structural characterizations showed the absence of undesired segregation of $\mathrm{CeO}_{2}$, which affected 


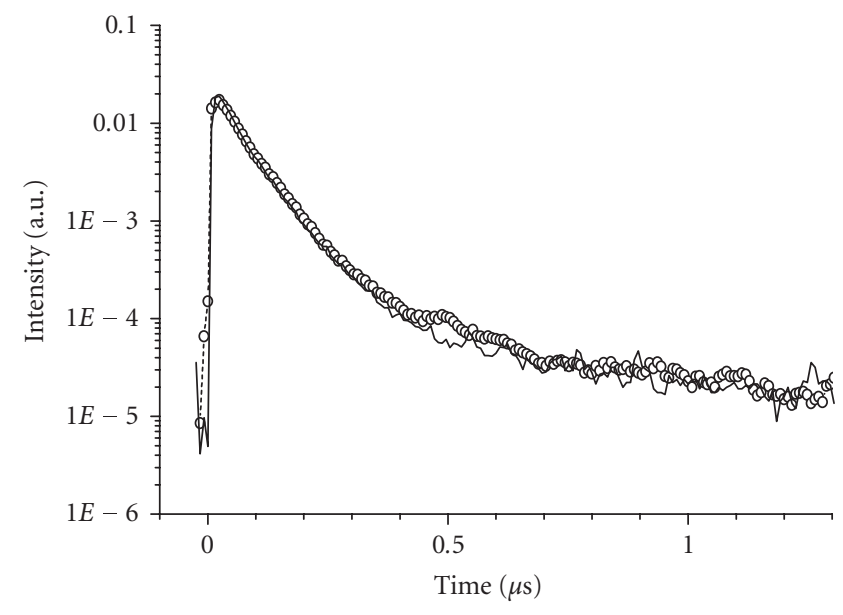

FIGURE 3: Experimental (solid line) and simulated (circles) emission decay curves at RT of Ce-doped SG ( $\mathrm{Ce}: \mathrm{Si}=1 \cdot 10^{-3}$ molar ratio) inverted opals $\left(\lambda_{\mathrm{exc}}=290 \mathrm{~nm} ; \lambda_{\mathrm{em}}=415 \mathrm{~nm}\right)$.

monolithic Ce-doped SG with the same RE content, indicating a homogeneous dispersion of RE in the matrix. This suggests that the nanometric dimensions of the bridges and junctions, which constitute the architecture of the inverted opal host matrix, favor the RE distribution avoiding the possible aggregation of $\mathrm{CeO}_{2}$.

The silica matrix environment of the luminescent $\mathrm{Ce}^{3+}$ centers does not significantly change in the inverted opal structure with respect to monolithic samples.

\section{REFERENCES}

[1] M. Nikl, K. Nitsch, E. Mihokova, et al., "Efficient radioluminescence of the $\mathrm{Ce}^{3+}$-doped Na-Gd phosphate glasses," Applied Physics Letters, vol. 77, no. 14, pp. 2159-2161, 2000.

[2] S. Baccaro, R. Dall'Igna, P. Fabeni, et al., " $\mathrm{Ce}^{3+}$ or $\mathrm{Tb}^{3+}$-doped phosphate and silicate scintillating glasses," Journal of Luminescence, vol. 87, pp. 673-675, 2000.

[3] T. Murata, M. Sato, H. Yoshida, and K. Morinaga, "Compositional dependence of ultraviolet fluorescence intensity of $\mathrm{Ce}^{3+}$ in silicate, borate, and phosphate glasses," Journal of NonCrystalline Solids, vol. 351, no. 4, pp. 312-316, 2005.

[4] M. Laroche, S. Girard, R. Moncorgé, M. Bettinelli, R. Abdulsabirov, and V. Semashko, "Beneficial effect of $\mathrm{Lu}^{3+}$ and $\mathrm{Yb}^{3+}$ ions in UV laser materials," Optical Materials, vol. 22, no. 2, pp. 147-154, 2003.

[5] E. Auffray, D. Bouttet, I. Dafinei, et al., "Cerium doped heavy metal fluoride glasses, a possible alternative for electromagnetic calorimetry," Nuclear Instruments and Methods in Physics Research, Section A, vol. 380, no. 3, pp. 524-536, 1996.

[6] G. E. Malashkevich, I. M. Melnichenko, E. N. Poddenezhny, and A. A. Boiko, "New optical centers of triply charged cerium ions in silica gel-glasses saturated with hydrogen," Journal of Non-Crystalline Solids, vol. 260, no. 1-2, pp. 141-146, 1999.

[7] K. Itoh, N. Kamata, T. Shimazu, C. Satoh, K. Tonooka, and K. Yamada, "Improved emission characteristics of $\mathrm{Tb}^{3+}$-doped sol-gel glasses by utilizing high solubility of terbium nitrate," Journal of Luminescence, vol. 87-89, pp. 676-678, 2000.
[8] A. Vedda, A. Baraldi, C. Canevali, et al., "Optical properties of $\mathrm{Ce}^{3+}$-doped sol-gel silicate glasses," Nuclear Instruments and Methods in Physics Research, Section A, vol. 486, no. 1-2, pp. 259-263, 2002.

[9] G. Blasse and B. C. Grabmaier, Luminescent Materials, Springer, Berlin, Germany, 1994.

[10] D. Di Martino, A. Vedda, G. Angella, et al., "Evidences of rare earth ion aggregates in a sol-gel silica matrix: the case of cerium and gadolinium," Chemistry of Materials, vol. 16, no. 17, pp. 3352-3356, 2004.

[11] C. Canevali, M. Mattoni, F. Morazzoni, et al., "Stability of luminescent trivalent cerium in silica host glasses modified by boron and phosphorus," Journal of the American Chemical Society, vol. 127, no. 42, pp. 14681-14691, 2005.

[12] A. Saitoh, S. Matsuishi, M. Oto, T. Miura, M. Hirano, and H. Hosono, "Elucidation of coordination structure around $\mathrm{Ce}^{3+}$ in doped $\mathrm{SiO}_{2}$ glasses using pulsed electron paramagnetic resonance: effect of phosphorus, boron, and phosphorusboron codoping," Physical Review B, vol. 72, no. 21, Article ID 212101, 2005.

[13] K. Arai, H. Namikawa, Y. Ishii, H. Imai, H. Hosono, and Y. Abe, "Nature of doping into pure silica glass by plasma torch CVD," Journal of Non-Crystalline Solids, vol. 95-96, pp. 609616, 1987.

[14] T. Jüstel, H. Nikol, and C. Ronda, "New developments in the field of luminescent materials for lighting and displays," Angewandte Chemie - International Edition, vol. 37, no. 22, pp. 3084-3103, 1998.

[15] J. Rocha and L. D. Carlos, "Microporous materials containing lanthanide metals," Current Opinion in Solid State and Materials Science, vol. 7, no. 3, pp. 199-205, 2003.

[16] B. J. Scott, G. Wirnsberger, and G. D. Stucky, "Mesoporous and mesostructured materials for optical applications," Chemistry of Materials, vol. 13, no. 10, pp. 3140-3150, 2001.

[17] J. Sauer, F. Marlow, B. Spliethoff, and F. Schüth, "Rare earth oxide coating of the walls of SBA-15," Chemistry of Materials, vol. 14, no. 1, pp. 217-224, 2002.

[18] M. J. A. de Dood, L. H. Slooff, A. Polman, A. Moroz, and A. van Blaaderen, "Modified spontaneous emission in erbiumdoped $\mathrm{SiO}_{2}$ spherical colloids," Applied Physics Letters, vol. 79, no. 22, pp. 3585-3587, 2001.

[19] S. V. Gaponenko, V. N. Bogomolov, E. P. Petrov, et al., "Spontaneous emission of dye molecules, semiconductor nanocrystals, and rare-earth ions in opal-based photonic crystals," Journal of Lightwave Technology, vol. 17, no. 11, pp. 2128-2137, 1999.

[20] Y. Xia, B. Gates, Y. Yin, and Y. Lu, "Monodispersed colloidal spheres: old materials with new applications," Advanced Materials, vol. 12, no. 10, pp. 693-713, 2000.

[21] J. M. Baker, "EPR and ENDOR in the lanthanides," in Electron Spin Resonance, vol. 13B, chapter 3, The Royal Society of Chemistry, Cambridge, UK, 1993.

[22] A. Abragam and B. Bleaney, Electron Paramagnetic Resonance of Transition Metal Ions, Clarendon Press, Oxford, UK, 1970.

[23] M. Yamaga, M. Honda, K. Shimamura, T. Fukuda, and T. Yosida, "Electron spin-resonance study on $\mathrm{Ce}^{3+}$ in $\mathrm{BaLiF}_{3}$," Journal of Physics Condensed Matter, vol. 12, no. 27, pp. 59175928, 2000.

[24] S. K. Misra and S. Isber, "EPR of the Kramers ions $\mathrm{Er}^{3+}, \mathrm{Nd}^{3+}$, $\mathrm{Yb}^{3+}$ and $\mathrm{Ce}^{3+}$ in $\mathrm{Y}\left(\mathrm{NO}_{3}\right)_{3} \cdot 6 \mathrm{H}_{2} \mathrm{O}$ and $\mathrm{Y}_{2}\left(\mathrm{SO}_{4}\right)_{3} \cdot 8 \mathrm{H}_{2} \mathrm{O}$ single crystals: study of hyperfine transitions," Physica B, vol. 253, no. 1-2, pp. 111-122, 1998.

[25] S. K. Misra, Y. Chang, and J. Felsteiner, "A calculation of effective $g$-tensor values for $R^{3+}$ ions in $\mathrm{RBa}_{2} \mathrm{Cu}_{3} \mathrm{O}_{7}-\delta$ and 
$\mathrm{RBa}_{2} \mathrm{Cu}_{4} \mathrm{O}_{8}(R=$ Rare Earth): low-temperature ordering of Rare-Earth moments," Journal of Physics and Chemistry of Solids, vol. 58, no. 1, pp. 1-11, 1997.

[26] M. Yamaga, M. Honda, N. Kawamata, T. Fujita, K. Shimamura, and T. Fukuda, "Site symmetry and crystal field of $\mathrm{Ce}^{3+}$ luminescent centres in $\mathrm{KMgF}_{3}$," Journal of Physics Condensed Matter, vol. 13, no. 14, pp. 3461-3473, 2001.

[27] M. Nikl, K. Nitsch, E. Mihokova, et al., "Efficient radioluminescence of the $\mathrm{Ce}^{3+}$-doped Na-Gd phosphate glasses," Applied Physics Letters, vol. 77, no. 14, pp. 2159-2161, 2000. 


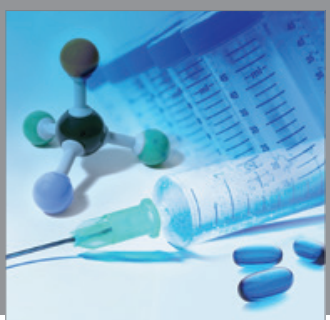

International Journal of

Medicinal Chemistry

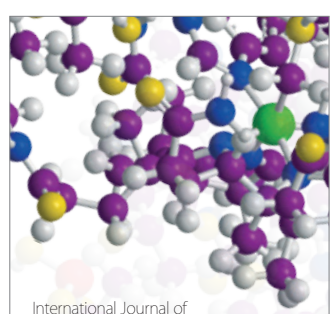

Carbohydrate Chemistry

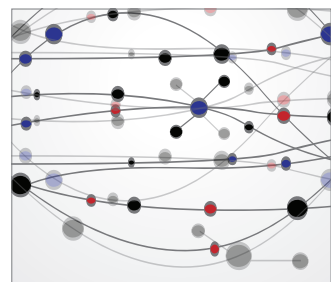

The Scientific World Journal
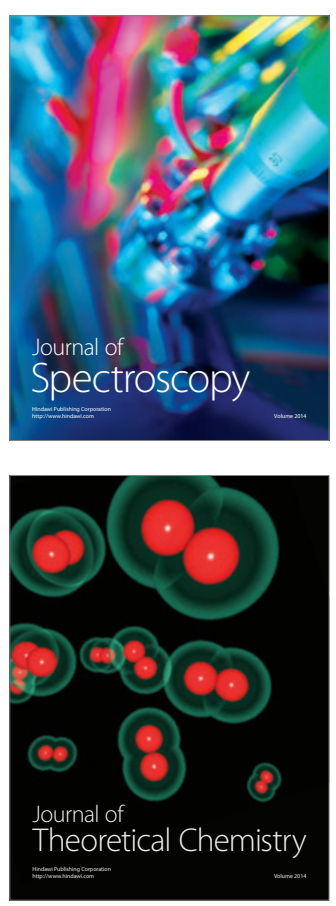
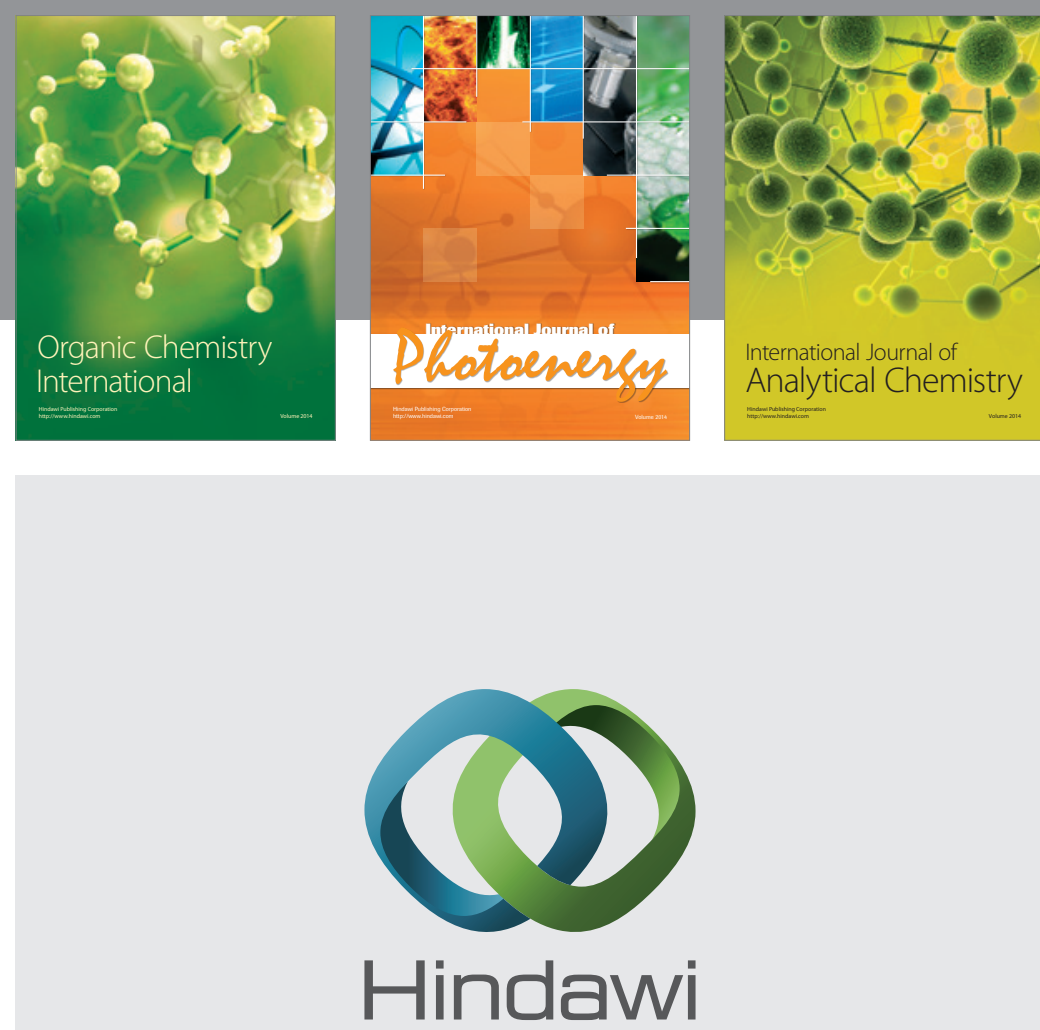

Submit your manuscripts at

http://www.hindawi.com
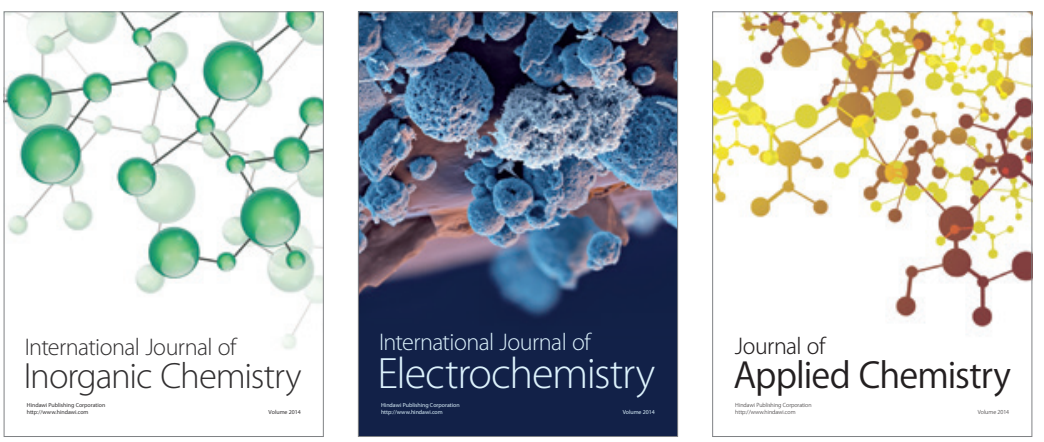

Journal of

Applied Chemistry
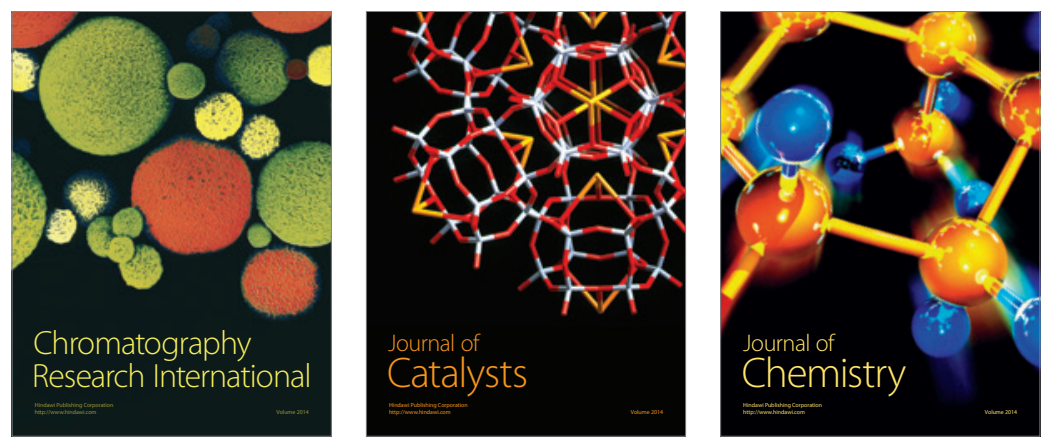
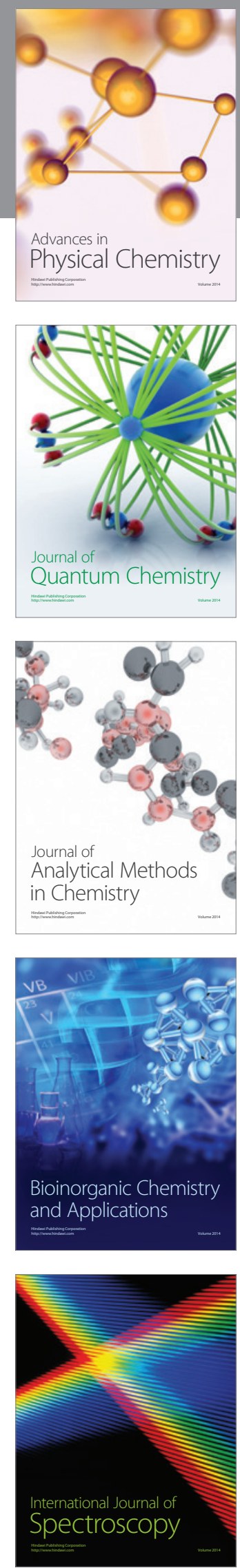